\title{
Validation of clinical control in COPD as a new tool for optimizing treatment
}

This article was published in the following Dove Press journal:

International Journal of COPD

\author{
Juan José Soler-Cataluña ${ }^{1,2}$ \\ Maribel Marzo 3 \\ Pablo Catalán' \\ Cristina Miralles' \\ Bernardino Alcazar ${ }^{2,4}$ \\ Marc Miravitlles 2,5 \\ 'Pneumology Department, Hospital \\ Arnau de Vilanova, Valencia, Spain; \\ ${ }^{2}$ CIBER of Respiratory Diseases \\ (CIBERES), Spain; ${ }^{3}$ Emergency \\ Department, Hospital General de \\ Requena, Valencia, Spain; ${ }^{4}$ Respiratory \\ Department, Hospital de Alta \\ Resolución de Loja, Granada, Spain; \\ ${ }^{5}$ Pneumology Department, University \\ Hospital Vall d'Hebron/Vall d'Hebron \\ Research Institute (VHIR), Barcelona, \\ Spain
}

Background: It has recently been proposed that the concept of clinical control in COPD may be useful for deciding treatment in COPD, but the original control criteria (OCC) were considered too restrictive.

Objective: Define and subsequently validate "modified" control criteria (MCC) of COPD. Method: Prospective observational study in COPD patients with a 1-year follow-up. Control was defined as the presence of low clinical impact and clinical stability. To evaluate clinical impact, the following clinical parameters were assessed: the degree of dyspnea, use of rescue medication, physical activity, and sputum color. Stability was assessed by clinical changes and exacerbations in the last 3 months. The COPD assessment test score and their changes were also evaluated as alternative control criteria. To define the MCC, adjustment for disease severity using BODEx index (MCC-B) or FEV $(\mathrm{MCC}-\mathrm{F})$ was evaluated, and the best cutoff point was established. Time to first combined event (emergency visit, hospitalization, or death) was analyzed to evaluate the predictive capacity of risk of the OCC, MCC-B, and MCC-F.

Results: We included 265 patients, 224 (83.9\%) men, with a mean age ( \pm SD) of $68 \pm 9$ years and $\mathrm{FEV}_{1}$ of $58 \% \pm 17 \%$. The proportion of controlled patients was higher using clinical MCC-B or MCC-F (61.5\% and 59.6\%) than OCC (27.5\%). Similar percentages were found using COPD assessment test scores. The time to the first combined event was significantly greater in controlled patients using MCC criteria ( $P<0.001$, all cases $)$. The predictive capacity of risk was similar in MCC-B (c-statistic $[\mathrm{C}]=0.639)$ and MCC-F $(\mathrm{C}=0.637)$ and higher than OCC $(\mathrm{C}=0.589)$.

Conclusions: The new MCC identified a higher number of controlled COPD patients. These patients have a better quality of life and lower risk of poor outcomes. The concept of control and the new MCC could be a useful tool to optimize therapy.

Keywords: COPD, control, CAT, outcomes

\section{Introduction}

One of the main therapeutic objectives of COPD is to achieve good disease control with few symptoms and low risk of exacerbations. ${ }^{1-3}$ However, in contrast with what occurs with asthma, ${ }^{3}$ the concept of control in COPD is not well characterized. A recent proposal defined control in COPD as "long term maintenance of a situation of low clinical impact adapted to the severity of the disease". 5 This definition includes the combination of two evaluative dimensions: one which is cross-sectional - clinical impact - or the repercussion the disease has on the patient, which should always be as little as possible, and the other is longitudinal - stability - understood as the absence of exacerbations or clinical worsening over time. ${ }^{6}$ The situation of control is approached as something that is desirable and potentially achievable for most COPD patients and can be potentially useful for dynamic adjustment of the treatment. Theoretically, controlled patients should present fewer symptoms, have a better health-related quality of life (HRQoL), and a lower risk
Correspondence: Marc Miravitlles Pneumology Department, University Hospital Vall d'Hebron/Vall d'Hebron Research Institute (VHIR), Barcelona, Spain

$\mathrm{Tel} / \mathrm{fax}+34932746083$

Email mmiravitlles@vhebron.net
International Journal of COPD 2018:13 3719-3731

3719

Dovepress if in 0

http://dx,doi.org/10.21471COPD.S178149 (c) (1) (5) 2018 Soler-Cataluña et al. This work is published and licensed by Dove Medical Press Limited. The full terms of this license are available at https://www.dovepress.com/terms.php cc. ${ }_{\mathrm{BY}} \mathrm{NC}_{\text {and }}$ incorporate the Creative Commons Attribution - Non Commercial (unported, v3.0) License (http://creativecommons.org/licenses/by-n/3.0/). By accessing the work you hereby accept the Terms. Non-commercial uses of the work are permitted without any further permission from Dove Medical Press Limited, provided the work is properly attributed. For permission for commercial use of this work, please see paragraphs 4.2 and 5 of our Terms (https://www.dovepress.com/terms.php). 
of future complications (fewer exacerbations, less disease progression, lower mortality) than noncontrolled patients.

In the initial proposal, some criteria were described to define control (original control criteria [OCC]) ${ }^{5,6}$ These OCC emerged from clinical experience and review of the literature, but they need to be refined and validated. Nibber et $\mathrm{al}^{7}$ recently evaluated this concept in a retrospective study using the registry of the Optimum Patient Care Research Database in the United Kingdom. According to the recommended clinical characteristics of the OCC, the proportion of controlled mild-moderate COPD patients was of only $4.5 \%$ while this proportion was $21 \%$ based on clinical questionnaires such as the COPD assessment test (CAT). According to clinical evaluation, no severe patients were controlled, with only $8.3 \%$ being identified if the control was defined using the CAT. ${ }^{7}$ Despite this low proportion of controlled patients, the time until the first exacerbation was longer. More recently, Miravitlles et $\mathrm{al}^{8}$ reported $32 \%$ of controlled patients in a cross-sectional, multicenter study. All of these results suggest that the concept of clinical control may be useful in COPD but the OCC proposed are likely too restrictive and should therefore be modified. In addition, a prospective, longitudinal validation of the predictive capacity of the risk of poor outcomes is needed.

The objectives of the present study were as follows: 1) to evaluate the OCC, and if deemed necessary, develop modified control criteria (MCC) evaluating the adequacy of the variables included in the original proposal, the different thresholds, the number of criteria needed, and the need for adjustment according to severity, and 2) validate the concept of control as a predictor of risk of poor outcomes.

\section{Methodology}

\section{Study design}

This was a prospective, observational study with a 1-year follow-up in a cohort of patients diagnosed with COPD.
All the cases were evaluated in the pneumology outpatient clinic on the initial visit (V0), at 3 months (V1), and at 1 year of follow-up (Vend). The study was conducted in accordance with the Declaration of Helsinki and it was approved by the Committee of Ethics and Clinical Investigation of the Hospital Arnau de Vilanova in Valencia, Spain. All patients provided written informed consent.

\section{Patients}

The study included patients $\geq 40$ years of age diagnosed with COPD defined by the presence of a history of smoking $>10$ pack-years, the $\mathrm{FEV}_{1}$, FVC after bronchodilation $<0.7$, and the presence of persistent respiratory symptoms. The exclusion criteria were as follows: active neoplastic disease, inability to carry out follow-up, patients participating in clinical trials, and all patients presenting an exacerbation within the previous 2 weeks. The recruitment was consecutive and all patients attending the outpatient clinic and fulfilling inclusion criteria were invited to participate.

\section{Adequacy of the original control criteria}

To evaluate the adequacy of the components of the concept of control, the thresholds, the number of criteria necessary, and the need for adjustment according to severity, clinical impact, and stability according to the OCC proposed by Soler-Cataluña et $\mathrm{al}^{6}$ (Table 1 ) were registered on each of the three visits and evaluated by two methods based on clinical variables or the use of questionnaires.

To evaluate the clinical impact with clinical variables, we recorded the degree of dyspnea using the modified scale of the Medical Research Council (mMRC), ${ }^{9}$ the use of rescue medication in the last week, sputum color, and the grade of self-reported physical activity. The rescue medication was categorically reported as: 1) used less than three times

Table I Initial proposal of criteria necessary to establish clinical impact

\begin{tabular}{|c|c|c|c|c|}
\hline & \multicolumn{2}{|c|}{$\begin{array}{l}\text { Level of severity: mild-moderate } \\
\text { (BODEx } \leq 4 \text { points) }\end{array}$} & \multicolumn{2}{|c|}{$\begin{array}{l}\text { Level of severity: severe-very severe } \\
\text { (BODEx }>5 \text { points) }\end{array}$} \\
\hline & Low clinical impact & High clinical impact & Low clinical impact & High clinical impact \\
\hline \multicolumn{5}{|l|}{ I. Clinical evaluation } \\
\hline Dyspnea (mMRC) & $0-1$ & $\geq 2$ & $0-2$ & $\geq 3$ \\
\hline Rescue medication & $\leq 3$ times in the last week & $>3$ times in the last week & $<2$ times a day & $\geq 2$ times a day \\
\hline Daily physical activity ${ }^{a}$ & $\geq 60$ minutes & $<60$ minutes & $\geq 30$ minutes & $<30$ minutes \\
\hline Sputum color & Absent or white & Dark & Absent or white & Dark \\
\hline \multicolumn{5}{|c|}{ 2. Questionnaires of clinical control (alternative evaluation) } \\
\hline CAT questionnaire & $\leq 10$ & $>10$ & $\leq 20$ & $>20$ \\
\hline CCQ questionnaire & $\leq 1$ & $>1$ & $\leq 2$ & $>2$ \\
\hline
\end{tabular}

Note: ${ }^{\mathrm{a}}$ Time walked per day, includes the total time that the patient walked both at home and outside.

Abbreviations: CAT, COPD assessment test; CCQ, Clinical COPD Questionnaire; mMRC, Modified Medical Research Council. 
a week; 2) greater than or equal to three times a week but less than twice a day; and 3) greater than or equal to twice a day. Physical activity was recorded in relation to walking: 1) $\geq 60$ minutes a day; 2) between 30 and 60 minutes a day; and 3) $<30$ minutes a day. ${ }^{10}$ Sputum color was described as "dark", if it showed any color (green, yellowish, brownish, etc.) or "clear", if whitish in color or absent. Stability was defined as the absence of exacerbations in the last 3 months and the absence of clinical worsening since the last medical visit.

The evaluation of impact was also recorded using the $\mathrm{CAT}$ in all the visits. The CAT score ranges from 0 to 40 points, with the higher the score the worse is the health of the patient. ${ }^{11}$

Stability was defined as the absence of exacerbations in the last 3 months and the absence of clinical worsening since the previous medical visit. Clinical worsening was considered when the patient referred feeling worse since last visit, and the absence of worsening was considered when the patient reported feeling better or the same. In the evaluation using clinical questionnaires, stability was considered when a change in the CAT from V0 and V1 was $\leq 2$ points. $^{12}$

Clinical control was established when the patient presented low impact and clinical stability at the 3-month visit (V1). Initially, control was evaluated according to the OCC for both clinical variables and CAT. In addition, other cutoffs were studied in an attempt to refine the tool, defining MCC. The initial definition of control had different thresholds for the clinical variables according to the severity of the patient, the BODE index (body mass index, obstruction, dyspnea, exercise), ${ }^{13}$ or the BODEx index (body mass index, obstruction, dyspnea, exacerbations). ${ }^{14}$ For the purpose of simplicity, in the current analysis, severity was evaluated based on the BODEx index or the post-bronchodilator $\mathrm{FEV}_{1}(\%)$. Spirometry was accepted provided that it had been performed within the last 6 months according to international criteria. ${ }^{15}$

\section{Validation of control: predictive capacity}

To validate clinical control we evaluated the capacity of both the OCC and the MCC to predict clinical outcomes. The principal variable analyzed was the time until the first composite event defined by the first appearance of any of the following outcomes: visit to the emergency department for an exacerbation, hospitalization, or death. The secondary variables evaluated included the time until the first exacerbation of any type (including outpatient exacerbations), the time until hospitalization, the CAT score at 1-year visit, and survival. An exacerbation of COPD was defined as any worsening in respiratory symptomatology requiring the use of antibiotics, systemic corticosteroids, visit to the emergency department, or hospitalization.

\section{Statistical analysis}

Quantitative variables are expressed as mean \pm SD and qualitative values are expressed as proportions. Analysis of variance was performed to compare the means between groups, and proportions were compared using the chi-squared test with Bonferroni correction. To evaluate the need for adjustment according to severity for the different variables in the evaluation of clinical impact, an ordinal Pearson correlation was performed for quantitative variables and a Spearman correlation was carried out for the qualitative variables. The mean and 95\% CI were calculated for the different CAT values according to different levels of severity. The median was calculated for qualitative variables. The impact threshold for CAT selected was the upper limit of normality of the $95 \%$ CI. Based on these thresholds, a receiver operating characteristic (ROC) curve was calculated to identify the potential dichotomic cutoff for the level of severity. The median was used to identify the thresholds for the qualitative variables. All these analyses were performed using the data obtained in the first visit (V0). Stability at 3 months of follow-up (V1) was analyzed using the presence or absence of exacerbations, significant changes in CAT during this period and the subjective opinion of the patients as to feeling worse (criterion of instability) or better or the same (criterion of stability). Finally, the proportion of patients controlled at 3 months according to the OCC and the MCC was calculated for both the clinical evaluation and CAT. Concordance between the clinical evaluation and the evaluation by CAT was evaluated using the Kappa concordance index (K).

To compare the risk of combined events, exacerbations, hospitalizations, or mortality, Cox survival analysis was performed, and the corresponding hazard ratio (HR) was calculated. ${ }^{16}$ The Kaplan-Meier method was used to obtain the survival curves, and the c-statistic $(\mathrm{C})$ was calculated to compare the predictive capacity of risk between the OCC and the MCC. The difference in the probability of being free of the combined event between the controlled and noncontrolled patients was estimated to be at least less of $10 \%$ with a type I error of $5 \%(\alpha=0.05)$, with a unilateral estimation and minimum power required of $80 \%(\beta=0.20)$. The expected proportion of losses was deemed to be $12 \%$. With this assumption, the calculated sample size was 262 patients. Results were considered statistically significant with a $P<0.05$. All the analyses were performed with the SPPS version 20.0 statistical package (IBM Analytics, Aerkomm, NY, USA). 


\section{Results}

Two hundred ninety patients were evaluated, of which 27 were excluded ( 3 patients did not sign the informed consent, 4 were already enrolled in a clinical trial, 17 had a recent exacerbation, and 3 had an active neoplasm). Finally, a total of 265 patients were included, 222 (83.9\%) being men with a mean age of $68 \pm 9$ years, with a post-bronchodilator $\mathrm{FEV}_{1}(\%)$ of $58 \% \pm 17 \%$. Table 2 shows the general characteristics of the patients according to the four quartiles of the BODEx index.

\section{Adequacy of the OCC}

\section{Pertinence of the variables included in the model}

To evaluate the pertinence of the variables proposed in the OCC, we analyzed the differences in the CAT scores and the risk of exacerbation for each category of these variables
(Table 3) and we studied collinearity among them. On determining that all the variables defining clinical impact and stability were related to the CAT scores and/or the risk of future exacerbations, these variables were included in the process of refinement and validation.

There was only a moderate correlation between dyspnea and physical activity $(r=0.52)$. No relevant collinearity was presented among the remaining variables of the model.

\section{Adequacy of the OCC}

\section{Need for adjustment for severity}

To establish whether the cutoffs of clinical impact of each variable should be adjusted for severity, we calculated the coefficient of correlation between each variable included in the definition of control and severity evaluated with the BODEx index or $\mathrm{FEV}_{1}(\%)$. This correlation was significantly

Table 2 Basal characteristics of the patients included in the study

\begin{tabular}{|c|c|c|c|c|c|c|}
\hline \multirow[t]{2}{*}{ Characteristics } & Total & $\begin{array}{l}\text { Mild } \\
\text { (BODEx: 0-2) }\end{array}$ & $\begin{array}{l}\text { Moderate } \\
\text { (BODEx: 3-4) }\end{array}$ & $\begin{array}{l}\text { Severe } \\
\text { (BODEx: 5-6) }\end{array}$ & $\begin{array}{l}\text { Very severe } \\
\text { (BODEx: 7-9) }\end{array}$ & \multirow[t]{2}{*}{$P$-value } \\
\hline & 265 & $176(66.4 \%)$ & $61(23.0 \%)$ & $22(8.3 \%)$ & $6(2.3 \%)$ & \\
\hline Age (years) & $68 \pm 9$ & $67 \pm 9$ & $69 \pm 9$ & $73 \pm 8$ & $75 \pm 3$ & 0.001 \\
\hline $\begin{array}{l}\text { Gender } \\
\text { - Men } \\
\text { - Women }\end{array}$ & $\begin{array}{l}222(83.8 \%) \\
43(16.2 \%)\end{array}$ & $\begin{array}{l}149(84.7 \%) \\
27(15.3 \%)\end{array}$ & $\begin{array}{l}49(80.3 \%) \\
12(19.7 \%)\end{array}$ & $\begin{array}{l}18(81.8 \%) \\
4(18.2 \%)\end{array}$ & $\begin{array}{l}6(100 \%) \\
-\end{array}$ & NS \\
\hline Active smoking & $86(32.5 \%)$ & $57(32.4 \%)$ & $23(37.7 \%)$ & $6(27.3 \%)$ & $0(0.0 \%)$ & NS \\
\hline Pack-years & $56 \pm 32$ & $53 \pm 32$ & $57 \pm 29$ & $64 \pm 29$ & $73 \pm 55$ & NS \\
\hline FEV, post-bronchodilator (\%) & $58 \pm 17$ & $66 \pm 14$ & $46 \pm 9$ & $36 \pm 9$ & $26 \pm 7$ & $<0.001$ \\
\hline FEV, post-bronchodilator $(\mathrm{mL})$ & $\mathrm{I}, 575 \pm 585$ & $\mathrm{I}, 8 \mid 4 \pm 526$ & $1,204 \pm 320$ & $897 \pm 292$ & $611 \pm 135$ & $<0.00 \mathrm{I}$ \\
\hline $\mathrm{FEV} / \mathrm{FVC}$ & $0.52 \pm 0.12$ & $0.56 \pm 0.10$ & $0.47 \pm 0.11$ & $0.36 \pm 0.11$ & $0.34 \pm 0.08$ & $<0.001$ \\
\hline $\begin{array}{l}\text { Dyspnea (mMRC) } \\
\text { - Grade } 0 \\
\text { - Grade I } \\
\text { - Grade } 2 \\
\text { - Grade } 3 \\
\text { - Grade } 4\end{array}$ & $\begin{array}{l}55(20.7 \%) \\
108(40.7 \%) \\
60(22.6 \%) \\
29(10.9 \%) \\
13(4.9 \%)\end{array}$ & $\begin{array}{l}49(29.5 \%) \\
86(51.8 \%) \\
27(16.3 \%) \\
4(2.4 \%) \\
0(0 \%)\end{array}$ & $\begin{array}{l}\text { I ( I.6\%) } \\
\text { I5 (24.6\%) } \\
28(45.9 \%) \\
\text { I5 (24.6\%) } \\
2(3.3 \%)\end{array}$ & $\begin{array}{l}0(0 \%) \\
0(0 \%) \\
2(9.1 \%) \\
10(45.4 \%) \\
10(45.4 \%)\end{array}$ & $\begin{array}{l}0(0 \%) \\
0(0 \%) \\
0(0 \%) \\
2(33.3 \%) \\
4(66.7 \%)\end{array}$ & $<0.001$ \\
\hline $\begin{array}{l}\text { Rescue medication } \\
-\leq 3 \text { times/week } \\
->3 \text { times/week and }<2 \text { times/day } \\
-\geq 2 \text { times/day }\end{array}$ & $\begin{array}{l}204(77.0 \%) \\
25(9.4 \%) \\
36(13.6 \%)\end{array}$ & $\begin{array}{l}\text { I } 49(84.6 \%) \\
14(7.9 \%) \\
13(7.4 \%)\end{array}$ & $\begin{array}{l}42(68.9 \%) \\
9(14.7 \%) \\
10(16.4 \%)\end{array}$ & $\begin{array}{l}12(54.5 \%) \\
2(9.1 \%) \\
8(36.4 \%)\end{array}$ & $\begin{array}{l}2(33.3 \%) \\
0(0.0 \%) \\
4(66.7 \%)\end{array}$ & $<0.001$ \\
\hline 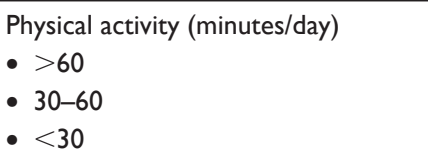 & $\begin{array}{l}86(32.4 \%) \\
93(35.1 \%) \\
86(32.4 \%)\end{array}$ & $\begin{array}{l}71(40.3 \%) \\
67(38.0 \%) \\
38(21.6 \%)\end{array}$ & $\begin{array}{l}13(21.3 \%) \\
20(32.8 \%) \\
28(45.9 \%)\end{array}$ & $\begin{array}{l}0(0 \%) \\
3(13.6 \%) \\
19(86.4 \%)\end{array}$ & $\begin{array}{l}2(33.3 \%) \\
3(50.0 \%) \\
1(16.7 \%)\end{array}$ & $<0.001$ \\
\hline $\begin{array}{l}\text { Sputum color } \\
\text { - White } \\
\text { - Dark }\end{array}$ & $\begin{array}{l}169(63.7 \%) \\
96(36.2 \%)\end{array}$ & $\begin{array}{l}122(69.3 \%) \\
54(30.7 \%)\end{array}$ & $\begin{array}{l}32(52.5 \%) \\
29(47.5 \%)\end{array}$ & $\begin{array}{l}14(63.6 \%) \\
8(36.4 \%)\end{array}$ & $\begin{array}{l}2(33.3 \%) \\
4(66.7 \%)\end{array}$ & NS \\
\hline Basal CAT & $12 \pm 8$ & $10 \pm 7$ & $15 \pm 7$ & $17 \pm 7$ & $17 \pm 8$ & $<0.001$ \\
\hline Exacerbations/last 3 months & $6 \mathrm{I}(23.0 \%)$ & $36(20.5 \%)$ & 19 (3I.1\%) & $3(13.6 \%)$ & $2(33.3 \%)$ & NS \\
\hline $\mathrm{N}^{\circ}$ exacerbations/last year & $1.10 \pm 1.80$ & $0.86 \pm 1.75$ & $1.56 \pm 1.76$ & $1.10 \pm 1.26$ & $3.33 \pm 3.01$ & 0.001 \\
\hline
\end{tabular}

Abbreviations: CAT, COPD assessment test; mMRC, Modified Medical Research Council; NS, non significant. 
Table 3 Comparison of the different variables included in the OCC with the impact measured with the basal CAT and future risk assessed as time until the first exacerbation of any nature

\begin{tabular}{|c|c|c|c|c|}
\hline \multirow[t]{2}{*}{ Criteria of clinical impact } & \multicolumn{2}{|c|}{ Basal clinical impact } & \multicolumn{2}{|c|}{ Future risk (time until exacerbation) } \\
\hline & Basal CAT & $P$-value & OR & $P$-value \\
\hline $\begin{array}{l}\text { - Dyspnea (mMRC) } \\
\text { - Grade } 0 \\
\text { - Grade I } \\
\text { - Grade } 2 \\
\text { - Grade } 3 \\
\text { - Grade } 4\end{array}$ & $\begin{array}{l}6.1 \pm 3.7 \\
9.5 \pm 5.9 \\
15.1 \pm 6.8 \\
18.7 \pm 6.7 \\
20.4 \pm 7.3\end{array}$ & $<0.0001$ & $\begin{array}{l}- \\
1.28(0.50-2.03) \\
1.01(0.59-1.70) \\
1.41(0.77-2.58) \\
2.90(1.42-5.91)\end{array}$ & 0.03 \\
\hline $\begin{array}{l}\text { - Rescue medication } \\
\circ \leq 3 \text { times/week } \\
\circ>3 \text { times/week, but }<2 \text { times/day } \\
\circ \geq 2 \text { times/day }\end{array}$ & $\begin{array}{l}10.6 \pm 6.9 \\
13.0 \pm 7.1 \\
15.7 \pm 8.0\end{array}$ & $<0.0001$ & $\begin{array}{l}- \\
1.82(1.10-3.03) \\
1.84(1.19-2.85)\end{array}$ & $<0.000 \mathrm{I}$ \\
\hline $\begin{array}{l}\text { - Physical activity (minutes/day) } \\
\circ>60 \\
\circ 30-60 \\
\circ<30\end{array}$ & $\begin{array}{l}8.4 \pm 5.4 \\
11.2 \pm 6.9 \\
15.5 \pm 7.8\end{array}$ & $<0.0001$ & $\begin{array}{l}- \\
1.34(0.90-1.98) \\
1.29(0.86-1.93)\end{array}$ & NS \\
\hline $\begin{array}{l}\text { - Sputum color } \\
\circ \text { White } \\
\circ \text { Dark }\end{array}$ & $\begin{array}{l}12.5 \pm 7.0 \\
16.4 \pm 8.3\end{array}$ & 0.005 & $\begin{array}{l} \\
\\
\end{array} .68(1.07-2.64)$ & 0.024 \\
\hline $\begin{array}{l}- \text { Basal CAT } \\
\circ 0-10 \text { points } \\
\circ 1 \mathrm{II}-20 \text { points } \\
\circ 21-30 \text { points } \\
\circ>30 \text { points }\end{array}$ & $\begin{array}{l}5.8 \pm 2.8 \\
14.6 \pm 2.6 \\
24.6 \pm 2.4 \\
32.0 \pm 0.8\end{array}$ & $<0.0001$ & $\begin{array}{l}- \\
\text { I. } 16(0.82-I .64) \\
\text { I.47(0.94-2.28) } \\
2.37(0.86-6.50)\end{array}$ & NS \\
\hline Criteria of stability & Basal CAT & $P$-value & OR & $P$-value \\
\hline $\begin{array}{l}\text { - Exacerbations last } 3 \text { months } \\
\circ \text { No } \\
\circ \text { Yes }\end{array}$ & $\begin{array}{l}\text { II. } 0 \pm 6.8 \\
13.6 \pm 8.8\end{array}$ & 0.011 & $\begin{array}{l} \\
\\
\end{array} .85(1.34-2.58)$ & $<0.000 \mathrm{I}$ \\
\hline $\begin{array}{l}\text { - Perception of improvement since last visit } \\
\circ \text { Better or the same } \\
\circ \text { Worse }\end{array}$ & $\begin{array}{l}10.7 \pm 7.2 \\
16.6 \pm 7.1\end{array}$ & $<0.0001$ & $\begin{array}{l} \\
- \\
1.37(0.91-1.91)\end{array}$ & NS \\
\hline $\begin{array}{l}\text { - CAT change } \\
0 \leq 2 \text { points } \\
0>2 \text { points }\end{array}$ & $\begin{array}{l}10.7 \pm 7.1 \\
16.6 \pm 7.2\end{array}$ & $<0.0001$ & - & 0.030 \\
\hline
\end{tabular}

Abbreviations: CAT, COPD assessment test; OCC, original control criteria; NS, non significant.

strong for dyspnea, moderate for CAT, and significant, albeit weak, for rescue medication and physical activity. To the contrary, there was no significant association with sputum color or the number of exacerbations (Table S1).

With the aim of identifying the best cutoff of the BODEx and $\mathrm{FEV}_{1}(\%)$ for adjustment for severity, an ROC curve was calculated for both the qualitative variables of impact and the CAT. In regard to CAT, Figure 1 shows the values obtained for each of the quartiles of the BODEx index and $\mathrm{FEV}_{1}(\%)$. The best cutoff for adjustment for severity in the CAT was a BODEx of 2 points with a sensitivity and specificity of $56 \%$ and $77 \%$, respectively. The cutoff of 4 proposed in the OCC had only a sensitivity of $22 \%$ and a specificity of $95 \%$. The same operation was done for the level of dyspnea, again finding that the best threshold to adjust for severity was to divide between quartile 1 of BODEx ( $\leq 2$ points) or subtract (BODEx: $\geq 3$ ). In the case of the $\mathrm{FEV}_{1} \%$, the best cutoff was $50 \%$, with a sensitivity of $53 \%$ and a specificity of $27 \%$.

\section{Adequacy of the OCC}

\section{Thresholds of the variables of clinical impact}

After the selection of the cutoff of severity for BODEx and $\mathrm{FEV}_{1}(\%)$, we investigated the best thresholds for each variable of the different levels of severity. The best cutoff for dyspnea in mild patients (BODEx $\leq 2$ or $\mathrm{FEV}_{1}(\%) \geq 50 \%$ ) was dyspnea $\leq 1$, being $\leq 2$ in severe patients, identical to what was proposed with the OCC. In the case of the rescue medication and physical activity, the threshold was similar in mild and severe patients. Adjustment for severity was not 

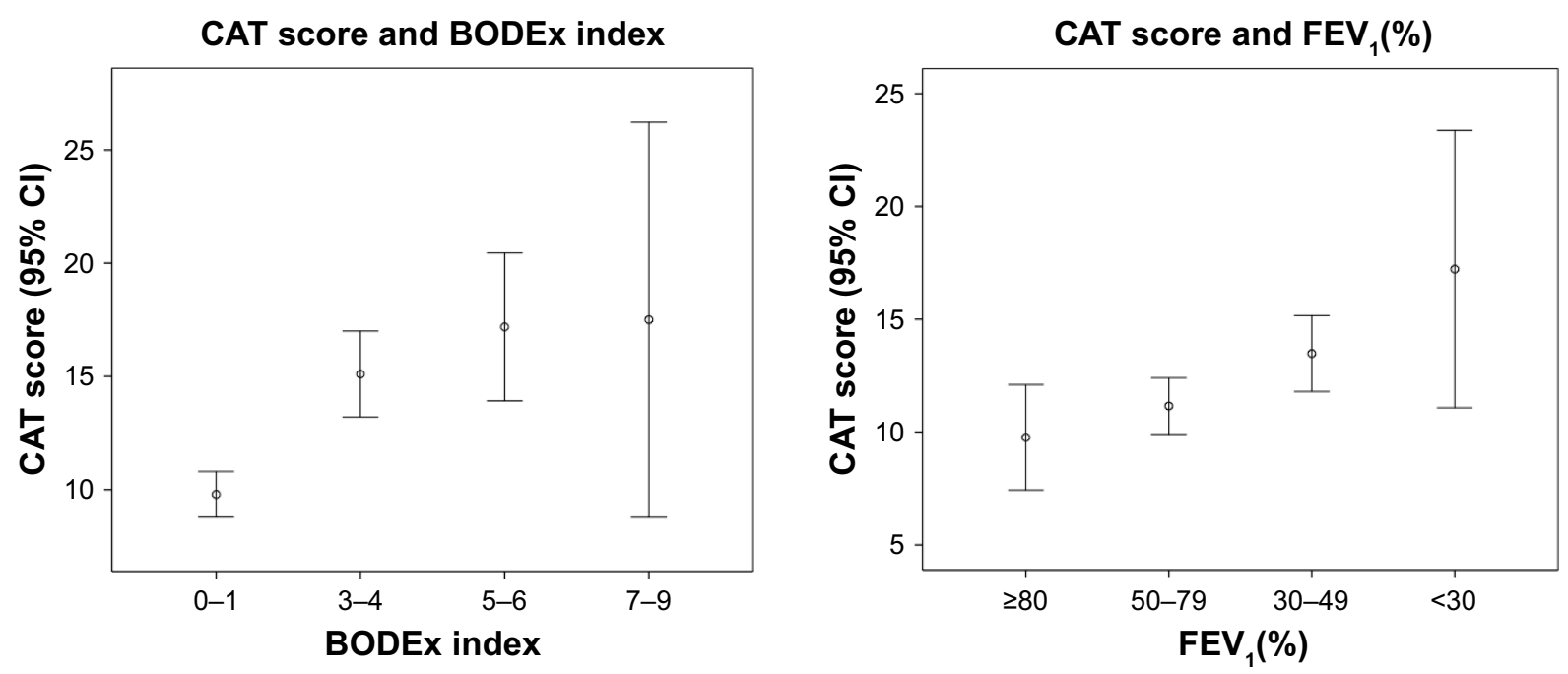

Figure I Distribution of CAT scores in patients grouped according to BODEx index and FEV $(\%)$. Abbreviation: CAT, COPD assessment test.

made for either sputum color or the number of exacerbations in the last 3 months due to a scarce correlation with the level of severity (explained in the previous section).

To evaluate the best cutoff for CAT, an ROC curve was made considering the clinical evaluations of the $\mathrm{MCC}$ adjusted for BODEx (MCC-B) and $\mathrm{FEV}_{1}(\%)$ (MCC-F) as the reference control criteria (explained in the "Creation of modified control criteria" section). Table S2 shows the sensitivity, specificity, and Youden index (Y) for each cutoff. The mean CAT for the group with a BODEx $\leq 2$ was $9.8(95 \% \mathrm{CI}$ : $8.8-10.8)$, and the best cutoff was 10 points. For patients with a BODEx $\geq 3$, the CAT was 15.6 (95\% CI: 14.0-17.2) and the best cutoff was 16 points. For the $\mathrm{FEV}_{1} \geq 50 \%$, the CAT was 10.8 (95\% CI: 9.7-11.9) and 13.9 (95\% CI: 12.3-15.5) for the cases with $\mathrm{FEV}_{1} \leq 49 \%$, choosing 10 and 16 points, respectively, as the cutoffs.

\section{Adequacy of the OCC}

\section{Number of criteria necessary to define clinical} impact

In order to identify the number of criteria necessary to define the clinical impact, we evaluated the grade of concordance between the definition of impact using the CAT and the number of clinical criteria fulfilled by each patient. The best overall concordance was obtained when three of the four criteria were fulfilled (Table S3). The best predictive capacity of a combined event was also obtained when at least three of the four criteria of impact were met $(\mathrm{C}=0.639$, for adjustment for BODEx and $\mathrm{C}=0.637$ on adjustment for $\mathrm{FEV}_{1}[\%]$; Table $\mathrm{S} 4$ ).

\section{Creation of modified control criteria}

We elaborated the MCC according to the need to adjust for severity and the thresholds identified in the previous sections (Table 4). Table 5 shows the proportion of patients controlled, and the clinical impact and stability according to the OCC, the MCC-B, and the MCC-F. The MCC provides notably higher values of controlled patients compared with the OCC, with no large differences between the MCC-B or MCC-F.

The index of overall concordance between the clinical evaluation and the CAT was 0.31 for the OCC, 0.37 for the MCC-B, and 0.42 for the MCC-F. Concordance of the clinical evaluation between MCC-B and MCC-F was 0.94, being 0.80 for the CAT.

\section{Control status and predictive capacity of risk}

The time to the first combined event in controlled patients was significantly longer compared with noncontrolled patients with any of the criteria used. Based on the clinical evaluation, the accumulated probability of having a combined event at 12 months in controlled compared with noncontrolled patients was $11 \%$ vs $22 \%$ for the OCC $(P=0.013), 14 \%$ vs $28 \%$ for the MCC-B $(P<0.001)$, and $13 \%$ vs $27 \%$ for the MCC-F ( $P<0.001$; Figure $2 \mathrm{~A})$. In the case of the CAT, the accumulated probability was $15 \%$ vs $22 \%$ for the OCC $(P=0.029), 15 \%$ vs $25 \%$ for the MCC-B $(P=0.007)$, and $15 \%$ vs $24 \%$ for the MCC-F $(P=0.009$; Figure 2B). Table 6 summarizes the HRs of all these diagnostic criteria.

The best predictive capacity of risk was obtained with the clinical evaluation with MCC-B $(\mathrm{C}=0.639)$ and MCC-F $(\mathrm{C}=0.637)$, both of which were greater than the clinical assessment with the OCC $(\mathrm{C}=0.589)$ and the CAT scores $(\mathrm{C}=0.572,0.592$, and 0.581 for the OCC, MCC-B, and MCC-F, respectively). 
Table 4 Modified control criteria (MCC), with adjustment for severity according to the BODEx index or FEV, $(\%)$

\begin{tabular}{|c|c|c|}
\hline \multirow[t]{2}{*}{ Clinical evaluation } & \multicolumn{2}{|c|}{ MCC with adjustment for the BODEx index or FEV $(\%)$} \\
\hline & $\begin{array}{l}\mathrm{FEV}_{1} \geq 50 \% \\
(\text { or BODEx } \leq 2 \text { ) }\end{array}$ & $\begin{array}{l}\text { FEV }, \leq 49 \% \\
(\text { or BODEx }>2)\end{array}$ \\
\hline \multicolumn{3}{|c|}{ Low clinical impact (at least three of the four criteria should be fulfilled) } \\
\hline Dyspnea & $0-1$ & $0-2$ \\
\hline Rescue medication & \multicolumn{2}{|c|}{$\leq 3$ times/week } \\
\hline Sputum color & \multicolumn{2}{|c|}{ White } \\
\hline Physical activity & \multicolumn{2}{|c|}{$\geq 30$ minutes/day } \\
\hline \multicolumn{3}{|c|}{ Clinical stability (both criteria should be fulfilled) } \\
\hline Subjective perception & \multicolumn{2}{|c|}{ Same or better } \\
\hline Exacerbations in the last 3 months & \multicolumn{2}{|c|}{ None } \\
\hline Control & \multicolumn{2}{|c|}{ Low impact+stability } \\
\hline \multicolumn{3}{|c|}{ Evaluation by Questionnaires (CAT) } \\
\hline \multicolumn{3}{|l|}{ Low impact } \\
\hline CAT & $0-10$ & $0-16$ \\
\hline \multicolumn{3}{|l|}{ Stability } \\
\hline CAT changes & \multicolumn{2}{|c|}{$\leq 2$ points } \\
\hline Control & \multicolumn{2}{|c|}{ Low impact+stability } \\
\hline
\end{tabular}

Abbreviations: CAT, COPD assessment test; MCC, modified control criteria.

Controlled patients also showed a significantly longer time until the first exacerbation compared with noncontrolled patients, with any of the three clinical evaluations analyzed. The predictive capacity of risk of exacerbation of the evaluation of control using the MCC-B and MCC-F with clinical variables was practically identical between the two types of criteria $(\mathrm{C}=0.614$ and 0.613 , respectively) and was greater than that of the OCC $(\mathrm{C}=0.571)$.

The evaluation of control with the CAT also showed a longer time until the first exacerbation in the MCC-B and MCC-F evaluations ( $P=0.013$ and $P=0.017$, respectively). However, we found no significant differences for the OCC.
The $\mathrm{C}$ values were $0.549,0.573$, and 0.561 for OCC, MCC-B, and MCC-F, respectively, being lower than all the variables in the clinical evaluation by MCC-B and MCC-F. Figure S1 shows the time to exacerbation for the MCC-F.

Controlled patients presented a longer time until hospitalization only for the MCC-B and MCC-F ( $P=0.015$ and $P=0.030$, respectively). There were no significant differences in the clinical evaluation by OCC $(P=0.223)$. In the evaluation with CAT, there were no significant differences for any criterion. The survival of controlled patients did not significantly differ with any of the three criteria evaluated, although the number of deaths was greatly reduced.

Table 5 Proportion of controlled patients according to the criteria used: OCC, MCC adjusted for the BODEx index, or MCC adjusted for FEV,

\begin{tabular}{|c|c|c|c|c|c|c|c|c|c|}
\hline \multirow{3}{*}{$\begin{array}{l}\text { Clinical } \\
\text { evaluation }\end{array}$} & \multicolumn{3}{|c|}{ OCC (adjustment for BODEx) } & \multicolumn{3}{|c|}{ MCC (adjustment for BODEx) } & \multicolumn{3}{|c|}{ MCC (adjustment for FEV $\%$ ) } \\
\hline & \multicolumn{2}{|l|}{ BODEx } & \multirow[t]{2}{*}{ Total } & \multicolumn{2}{|l|}{ BODEx } & \multirow[t]{2}{*}{ Total } & \multicolumn{2}{|l|}{ FEV $\%$} & \multirow[t]{2}{*}{ Total } \\
\hline & $\leq 4$ & $>4$ & & $\leq 2$ & $>2$ & & $\geq \mathbf{5 0} \%$ & $<\mathbf{5 0} \%$ & \\
\hline Low impact & $84(35.4 \%)$ & $3(10.7 \%)$ & 87 (32.8\%) & $158(89.8 \%)$ & 48 (53.9\%) & $206(77.7 \%)$ & $145(81.0 \%)$ & $52(60.5 \%)$ & $197(74.3 \%)$ \\
\hline Stability & $166(70.0 \%)$ & $10(35.7 \%)$ & $176(66.4 \%)$ & $135(76.7 \%)$ & $4 \mathrm{I}(46.1 \%)$ & $176(66.4 \%)$ & 127 (70.9\%) & 49 (57.0\%) & $176(66.4 \%)$ \\
\hline Control & 70 (29.5\%) & $3(10.7 \%)$ & $73(27.5 \%)$ & $128(72.7 \%)$ & 35 (39.3\%) & $163(61.5 \%)$ & $115(64.2 \%)$ & $43(50.0 \%)$ & I $58(59.6 \%)$ \\
\hline \multirow{2}{*}{$\begin{array}{l}\text { Evaluation } \\
\text { by CAT }\end{array}$} & \multicolumn{2}{|l|}{ BODEx } & \multirow[t]{2}{*}{ Total } & \multicolumn{2}{|l|}{ BODEx } & \multirow[t]{2}{*}{ Total } & \multicolumn{2}{|l|}{ FEV $\%$} & \multirow[t]{2}{*}{ Total } \\
\hline & $\leq 4$ & $>4$ & & $\leq 2$ & $>2$ & & $\geq \mathbf{5 0} \%$ & $<\mathbf{5 0} \%$ & \\
\hline Low impact & I 37 (57.3\%) & 19 (67.9\%) & $156(58.4 \%)$ & II 3 (64.2\%) & 57 (64.0\%) & I 70 (64.2\%) & 107 (59.8\%) & $57(66.3 \%)$ & 164 (61.9\%) \\
\hline Stability & I 80 (76.3\%) & $18(64.3 \%)$ & I 98 (75.0\%) & I 34 (77.5\%) & $63(70.8 \%)$ & I 97 (75.2\%) & I39 (78.1\%) & $58(68.2 \%)$ & $197(74.9 \%)$ \\
\hline Control & 124 (52.5\%) & 12 (42.9\%) & | 36 (5 |.5\%) & 105 (59.7\%) & 48 (53.9\%) & I 53 (57.7\%) & 100 (55.9\%) & 49 (57.0\%) & I 49 (56.2\%) \\
\hline
\end{tabular}

Note: Bold highlights the percentage of patients controlled in the different classifications.

Abbreviations: CAT, COPD assessment test; MCC, modified control criteria; OCC, original control criteria. 


\section{Time to combined event \\ Modified control criteria with adjustment for $\mathrm{FEV}_{1} \%$ \\ (MCC-F)}
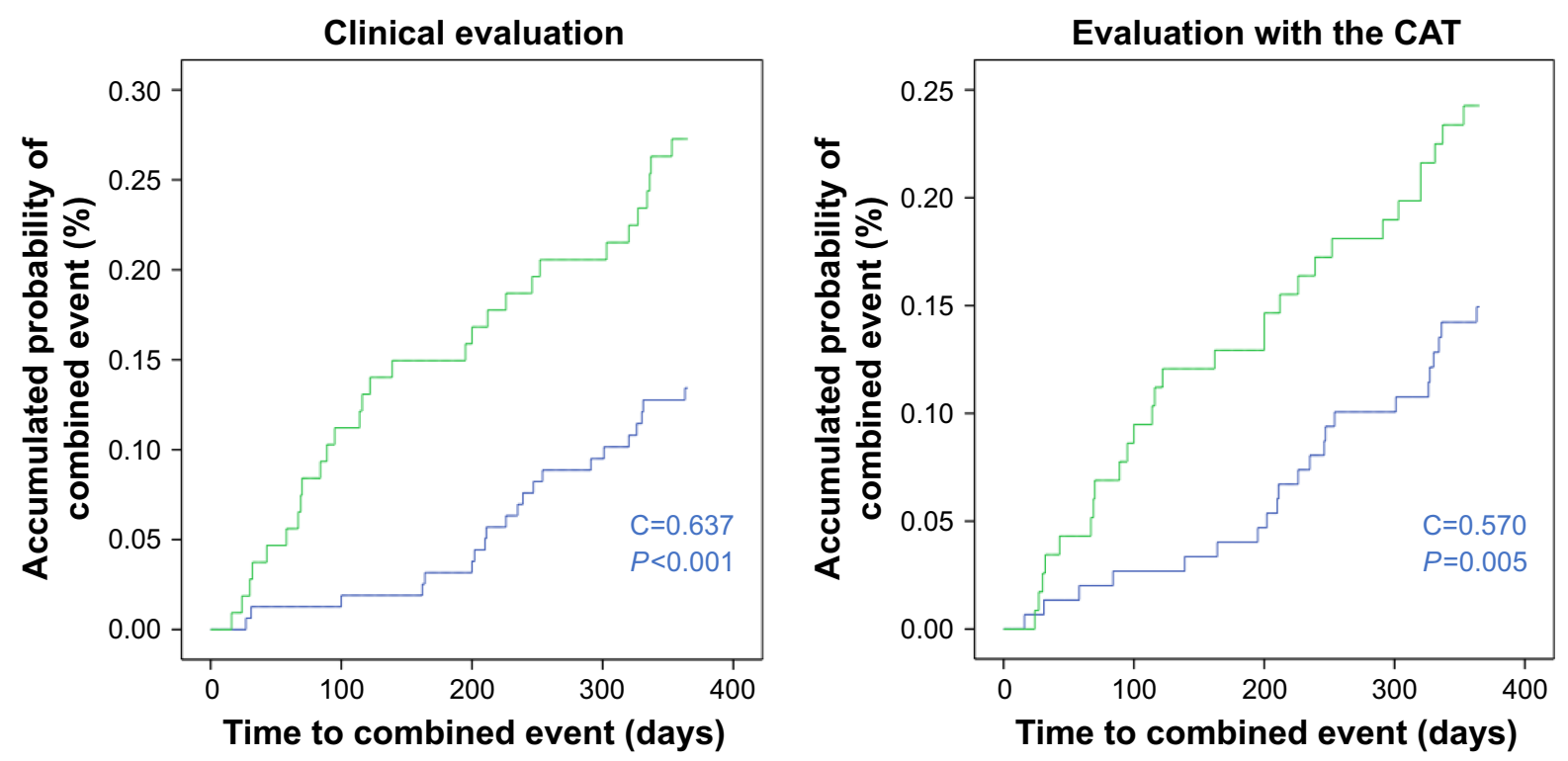

$\neg$ Control $\neg$ No

Figure 2 Accumulated probability of combined event in patients controlled or noncontrolled according to modified criteria of control adjusted by FEV $(\%)$. Notes: (A) control was defined by clinical evaluation; (B) control was defined using the CAT scores.

Finally, the CAT at 12 months was significantly inferior (better) with all the criteria used in controlled patients (Table S5).

\section{Discussion}

The results of this study indicate that the concept of control in COPD is useful and achievable in most patients. The findings confirm that the OCC are too restrictive, while in contrast, the new proposal of MCC seems to be more adequate and correlates very well with different clinical outcomes.
The application of the new MCC notably increased the proportion of controlled patients to up to $60 \%$ in both mild and severe patients. In addition, controlled patients showed a lower risk of complications with a longer time to the first combined event, the first exacerbation and hospitalization, and a better HRQoL at 1 year of follow-up. Independent of the type of adjustment for severity made, the predictive capacity of risk of the MCC was notably greater than that of the OCC, with clinical evaluation always being a better predictor of risk than the CAT evaluation.

Table 6 Hazard ratios of noncontrolled compared to controlled patients according to the different criteria used

\begin{tabular}{|c|c|c|c|c|c|c|}
\hline \multirow[t]{2}{*}{ Clinical evaluation } & \multicolumn{2}{|c|}{ OCC } & \multicolumn{2}{|c|}{ MCC (BODEx) } & \multicolumn{2}{|c|}{$\operatorname{MCC}\left(\right.$ FEV $\left._{1}\right)$} \\
\hline & HR & $95 \% \mathrm{Cl}$ & HR & $95 \% \mathrm{Cl}$ & HR & $95 \% \mathrm{Cl}$ \\
\hline Time to combined event & 2.30 & $|| 7-4.5 \mid$. & 2.54 & $1.57-4.13$ & 2.50 & $1.53-4.07$ \\
\hline Time to exacerbation & 1.71 & $1.17-2.49$ & 2.01 & $1.47-2.75$ & 2.01 & I.47-2.74 \\
\hline Time to hospitalization & 1.79 & $0.74-4.32$ & 2.37 & $1.19-4.69$ & 2.18 & $\mid .10-4.31$ \\
\hline Survival & 3.68 & $0.47-28.7$ & 2.85 & $0.85-9.50$ & 2.68 & $0.80-8.92$ \\
\hline Evaluation by the CAT & HR & $95 \% \mathrm{Cl}$ & HR & $95 \% \mathrm{Cl}$ & HR & $95 \% \mathrm{Cl}$ \\
\hline Time to combined event & 1.66 & $1.02-2.69$ & 1.88 & $1.17-3.04$ & 1.79 & $1.11-2.90$ \\
\hline Time to exacerbation & 1.29 & $0.95-1.76$ & 1.47 & $1.08-2.01$ & 1.42 & $1.05-1.94$ \\
\hline Time to hospitalization & 1.40 & $0.7 \mathrm{I}-2.75$ & 1.83 & $0.93-3.61$ & 1.73 & $0.88-3.41$ \\
\hline Survival & 1.42 & $0.45-4.46$ & 1.32 & $0.43-4.11$ & 1.28 & $0.4 \mid-3.97$ \\
\hline
\end{tabular}

Notes: HR, risk attributable to presenting an event in noncontrolled patients vs controlled patients; gray shading indicates statistical significance.

Abbreviations: CAT, COPD assessment test; MCC, modified control criteria; OCC, original control criteria. 
Niebber et $\mathrm{al}^{7}$ were the first to evaluate the OCC proposed by Soler-Cataluña et $\mathrm{al}^{5,6}$ in a population of COPD patients in the United Kingdom. The proportion of controlled patients was only $4.5 \%$ with the clinical approach and $21 \%$ with the CAT evaluation. More recently, Miravitlles et al ${ }^{8}$ also evaluated the same concept in an international, multicenter study, obtaining overall values of control of $32 \%$ for clinical evaluation and $37 \%$ for CAT. The present study showed similar results, with a proportion of controlled patients of only $27.5 \%$ using the clinical evaluation of the OCC $(29.5 \%$ for mild patients and $10.7 \%$ for severe patients) and of $50 \%$ with the CAT evaluation. All these studies indicate that the original proposal of control was probably too restrictive and should be refined.

The present study prospectively assessed the pertinence of the diagnostic criteria and the predictive value of the concept of control in COPD. First, each of the components of the original proposal was evaluated, and the potential threshold for each variable and the number of criteria necessary as well as the need for adjustment based on severity were identified. From this analysis we developed the MCC, which are simpler and more homogeneous. The main difference compared with the OCC was found in the need for adjustment according to severity. The OCC adjustment for severity was made using the BODE or BODEx index for all the components, with the exception of sputum color, with a cutoff of 4 . The MCC required adjustment only for the level of dyspnea or the CAT, and the cutoff was reduced to 2 for the BODEx index, thereby simplifying the proposal.

It is of interest that our study evaluated severity according to both the BODEx (MCC-B) index and the FEV ${ }_{1}(\%)$ (MCC-F). The predictive capacity of the MCC-B and MCC-F models was very similar between the two and was much greater than the OCC, and therefore, the stratification of mild/severe patients may potentially be made with both approaches. One of the previous criticisms regarding adjustment for severity lay in the fact that BODEx is a multidimensional index that already includes dyspnea and exacerbations, which are variables used to evaluate control. From this perspective we believe that the MCC-F provides more complementary information and will likely be more frequently used in clinical practice because the use of $\mathrm{FEV}_{1}(\%)$ is more generalized as a criterion of severity. In a recent clinical audit in Spain, only $6.2 \%$ of medical professionals used the BODEx for the classification of severity in COPD while $81.3 \%$ used the $\mathrm{FEV}_{1}(\%){ }^{17}$

With the use of the MCC, clinical control was achieved in approximately $60 \%$ of the patients, with similar values for both the clinical evaluation and the CAT questionnaire. However, the concordance between the two was moderate (K 0.37 for MCC-B and 0.42 for MCC-F), leading to doubts as to which of the two approaches should be used. In patients with asthma, the concordance between the clinical evaluation made by medical professionals and the Asthma Control Test is not elevated $(\mathrm{K}=0.42) .{ }^{18}$ Despite this, the Global Initiative for Asthma does not prioritize either of the two evaluations. ${ }^{4}$ On evaluating the predictive capacity of clinical evaluation in our study, it was always found to be better than the CAT ( $\mathrm{C}=0.64$ vs $\mathrm{C}=0.58$ ), and it therefore seems recommendable to use this evaluation as the first option and the CAT as an alternative approach.

The objectives of treatment in COPD include reducing the symptoms, improving the HRQoL, and diminishing the risk of future complications with a lower rate of exacerbations, less disease progression, and greater survival. ${ }^{1-3}$ The concept of control in COPD that we propose combines many of these concepts, and moreover, does so from a dynamic perspective, which can be assessed on each clinical visit and modified with the treatment. In the present study the controlled patients showed a better HRQoL with a CAT notably inferior after 1 year of follow-up to that of noncontrolled patients, and the risk of future complications was also markedly lower. On using the MCC-F the quotient of risk of presenting the first combined event was 2.5 -fold greater in noncontrolled patients while the risk of exacerbation and hospitalization doubled in the absence of control.

\section{Limitations}

Our study has several limitations. The sample size of severe patients was very small; therefore, the interpretation of results in this particular subgroup should be made with caution. Similarly, most patients were men, and may not be extrapolated to women. We did not find any significant difference in survival between controlled and uncontrolled patients, although the length of follow-up was only 12 months and the number of deaths was too low to establish comparisons. Further studies are clearly needed to externally validate our results, evaluating the impact of treatment, with a longer follow-up and including more severe patients and women. Nonetheless, these initial results open the possibility of considering clinical control as a new evaluative element in the follow-up of disease.

\section{Conclusion}

The present study prospectively validates the concept of control in COPD and proposes new control criteria, which 
are easy to use in clinical practice. Controlled COPD patients present fewer symptoms, have a better HRQoL and a lower risk of future complications. We therefore suggest that clinical control may be a new desirable and achievable therapeutic objective for most patients with COPD and may thus become a useful dynamic tool for clinical decision making.

\section{Disclosure}

JJSC has received speaker fees from AstraZeneca, Boehringer Ingelheim, Chiesi, Esteve, Ferrer, GSK, Menarini, Novartis, and Pfizer, and consulting fees from Air Liquide, Boehringer Ingelheim, Chiesi, GSK, AstraZeneca, Ferrer, and Novartis. BA reports personal fees and grants from Novartis AG, personal fees from BoehringerIngelheim, personal fees from GSK, personal fees from AstraZeneca, grants and personal fees from Menarini, outside the submitted work; M Miravitlles has received speaker or consulting fees from (in alphabetical order) Bial, Boehringer Ingelheim, Chiesi, Cipla, CSL Behring, Laboratorios Esteve, Gebro Pharma, GlaxoSmithKline, Grifols, Menarini, Mereo Biopharma, Novartis, pH Pharma, Rovi, TEVA, Verona Pharma and Zambon, and research grants from GlaxoSmithKline and Grifols, all outside the submitted work. The authors report no other conflicts of interest in this work.

\section{References}

1. Vogelmeier CF, Criner GJ, Martínez FJ, et al. Global Strategy for the Diagnosis, Management, and Prevention of Chronic Obstructive Lung Disease 2017 Report: GOLD Executive Summary. Arch Bronconeumol. 2017;53(3):128-149.

2. Miravitlles M, Soler-Cataluña JJ, Calle M. Spanish COPD guidelines (GesEPOC) 2017. Pharmacological treatment of stable chronic obstructive pulmonary disease. Arch Bronconeumol. 2017;53:324-335.

3. Wedzicha JA, Calverley PMA, Albert RK, et al. Prevention of COPD exacerbations: a European Respiratory Society/American Thoracic Society guideline. Eur Respir J. 2017;50(3):1602265.
4. GINA report. Global strategy for asthma management and prevention. 2017. Available from: http://www.ginasthma.org/. Accessed July 3, 2018.

5. Soler-Cataluña JJ, Alcázar-Navarrete B, Miravitlles M. The concept of control in COPD: a new proposal for optimising therapy. Eur Respir J. 2014;44(4):1072-1075.

6. Soler-Cataluña JJ, Alcázar-Navarrete B, Miravitlles M. The concept of control of COPD in clinical practice. Int J Chron Obstruct Pulmon Dis. 2014;9:1397-1405.

7. Nibber A, Chisholm A, Soler-Cataluña JJ, Alcázar B, Price D, Miravitlles M. Validating the concept of COPD control: a real-world cohort study from the United Kingdom. COPD. 2017;14(5):504-512.

8. Miravitlles M, Sliwinski P, Rhee CK, et al. Evaluation of criteria for clinical control in a prospective, international, multicenter study of patients with COPD. Respir Med. 2018;136:8-14.

9. Bestall JC, Paul EA, Garrod R, Garnham R, Jones PW, Wedzicha JA. Usefulness of the medical research council (MRC) dyspnoea scale as a measure of disability in patients with chronic obstructive pulmonary disease. Thorax. 1999;54(7):581-586.

10. Ramon MA, Esquinas C, Barrecheguren M, et al. Self-reported daily walking time in COPD: relationship with relevant clinical and functional characteristics. Int J Chron Obstruct Pulmon Dis. 2017;12: $1173-1181$.

11. Jones PW, Harding G, Berry P, et al. Development and first validation of the COPD Assessment Test. Eur Respir J. 2009;34(3):648-654.

12. Kon SS, Canavan JL, Jones SE, et al. Minimum clinically important difference for the COPD Assessment Test: a prospective analysis. Lancet Respir Med. 2014;2(3):195-203.

13. Celli BR, Cote CG, Marín JM, et al. The body-mass index, airflow obstruction, dyspnea, and exercise capacity index in chronic obstructive pulmonary disease. $N$ Engl J Med. 2004;350(10):1005-1012.

14. Soler-Cataluña JJ, Martínez-García MA, Sánchez LS, Tordera MP, Sánchez PR. Severe exacerbations and BODE index: two independent risk factors for death in male COPD patients. Respir Med. 2009; 103(5):692-699.

15. Miller MR, Hankinson J, Brusasco V, et al. Standardisation of spirometry. Eur Respir J. 2005;26(2):319-338.

16. Cox DR. Regression models and life tables. J R Stat Soc. 1972;B34: $187-220$.

17. Calle Rubio M, Alcázar Navarrete B, Soriano JB, et al. Clinical audit of COPD in outpatient respiratory clinics in Spain: the EPOCONSUL study. Int J Chron Obstruct Pulmon Dis. 2017;12:417-426.

18. Thomas M, Kay S, Pike J, et al. The Asthma Control Test (ACT) as a predictor of GINA guideline-defined asthma control: analysis of a multinational cross-sectional survey. Prim Care Respir J. 2009;18(1): $41-49$. 


\section{Supplementary materials}

Table SI Correlation coefficient between the variables included in the model and the level of severity measured by BODEx index or $\mathrm{FEV}_{1}(\%)$

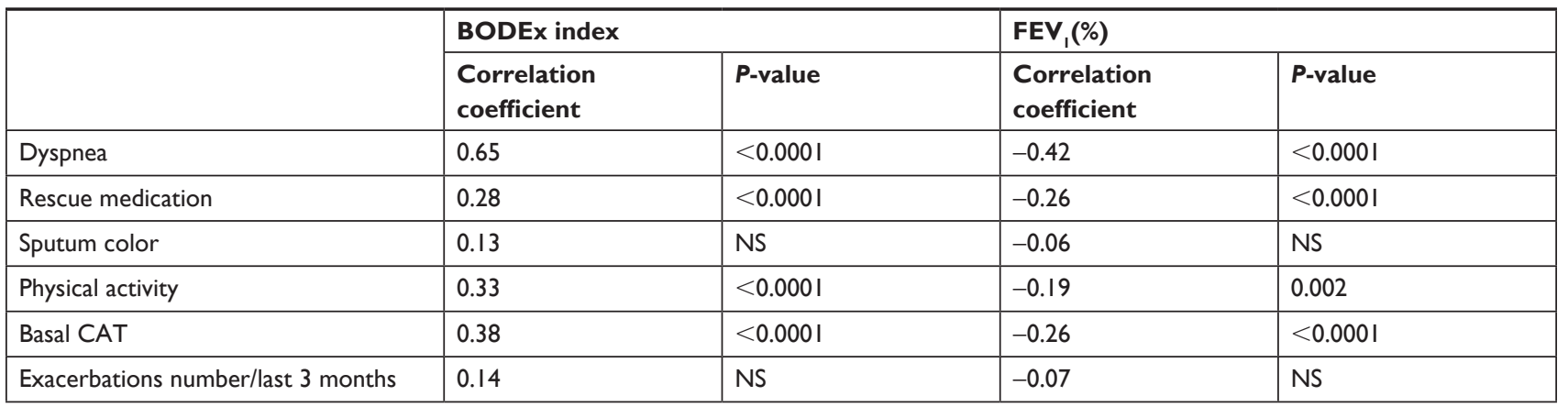

Abbreviations: CAT, COPD assessment test; NS, non significant.

Table S2 Sensitivity, specificity, and Youden index of different cutoff points for CAT score

\begin{tabular}{|c|c|c|c|c|c|c|c|c|c|c|c|c|}
\hline \multirow[t]{2}{*}{ CAT } & \multicolumn{3}{|c|}{ BODEx $\leq 2$} & \multicolumn{3}{|c|}{ BODEx $\geq 3$} & \multicolumn{3}{|c|}{ FEV $_{1} \geq \mathbf{5 0} \%$} & \multicolumn{3}{|c|}{ FEV $_{1} \leq 49 \%$} \\
\hline & $\mathbf{S}$ & Sp & $\mathbf{Y}$ & $\mathbf{S}$ & Sp & $\mathbf{Y}$ & $\mathbf{S}$ & Sp & $\mathbf{Y}$ & $\mathbf{S}$ & Sp & $\mathbf{Y}$ \\
\hline$\leq 5$ & 87.5 & 35.9 & 23.4 & 100 & 22.9 & 22.9 & 92.2 & 35.7 & 27.9 & 97.7 & 30.2 & 27.9 \\
\hline$\leq 6$ & 85.4 & 42.2 & 27.6 & 100 & 28.6 & 28.6 & 90.6 & 42.6 & 33.2 & 97.7 & 34.9 & 32.6 \\
\hline$\leq 7$ & 81.3 & 48.4 & 29.7 & 94.4 & 31.4 & 25.8 & 84.4 & 49.6 & 34.0 & 95.3 & 37.2 & 32.5 \\
\hline$\leq 8$ & 79.2 & 57.0 & 36.2 & 90.7 & 31.4 & 22.1 & 82.8 & 57.4 & 40.2 & 90.7 & 41.9 & 32.6 \\
\hline$\leq 9$ & 75.0 & 62.5 & 37.5 & 85.2 & 34.3 & 19.5 & \begin{tabular}{|l|}
79.7 \\
\end{tabular} & 63.5 & 43.2 & 83.7 & 44.2 & 27.9 \\
\hline$\leq 10$ & 72.9 & 69.5 & 42.4 & 81.5 & 42.9 & 24.4 & 78.1 & 71.3 & 49.4 & 79.1 & 51.2 & 30.3 \\
\hline$\leq 11$ & 62.5 & 74.2 & 36.7 & 79.6 & 51.4 & 31.0 & 68.8 & 75.7 & 44.5 & 79.1 & 60.5 & 39.6 \\
\hline$\leq 12$ & 60.4 & 78.1 & 38.5 & 74.1 & 65.7 & 39.8 & 62.5 & 81.8 & 44.2 & 76.7 & 65.1 & 41.8 \\
\hline$\leq 13$ & 52.1 & 80.5 & 32.6 & 72.2 & 68.6 & 40.8 & 56.3 & 84.3 & 40.6 & 74.4 & 67.4 & 41.8 \\
\hline$\leq 14$ & 50.0 & 82.8 & 32.8 & 70.4 & 77.1 & 47.5 & 54.7 & 86.1 & 40.8 & 72.1 & \begin{tabular}{|l|}
76.7 \\
\end{tabular} & 48.8 \\
\hline$\leq 15$ & 43.8 & 85.9 & 29.7 & 68.5 & 82.9 & 51.4 & 50.0 & 89.6 & 39.6 & 69.8 & 81.4 & 51.2 \\
\hline$\leq 16$ & 41.7 & 89.1 & 30.8 & 63.0 & 94.3 & 57.3 & 42.2 & 90.4 & 32.6 & 65.1 & \begin{tabular}{|l|}
90.7 \\
\end{tabular} & 55.8 \\
\hline$\leq 17$ & 39.6 & 89.8 & 29.4 & 55.6 & 94.3 & 49.9 & 39.1 & 91.3 & 30.4 & 58.1 & 90.7 & 48.8 \\
\hline$\leq 18$ & 35.4 & 93.0 & 28.4 & 50.0 & 94.3 & 44.3 & 32.8 & 93.0 & 25.8 & 53.5 & 93.0 & 46.5 \\
\hline$\leq 19$ & 31.3 & 94.5 & 25.8 & 42.6 & 94.3 & 36.9 & 25.0 & 94.8 & 19.8 & 51.2 & 93.0 & 44.2 \\
\hline$\leq 20$ & 25.0 & 95.3 & 20.3 & 35.2 & 94.3 & 29.5 & 17.2 & 95.7 & 12.9 & 46.5 & 93.0 & 39.5 \\
\hline
\end{tabular}

Note: The shading indicates the best cut offs identified by the analysis.

Abbreviations: CAT, COPD assessment test; S, sensitivity; Sp, specificity; Y, Youden index.

Table S3 Agreement between clinical impact evaluated by clinical assessment or by CAT (Kappa index), according to the number of criteria needed to define clinical control

\begin{tabular}{|c|c|c|c|c|c|c|}
\hline \multirow{3}{*}{$\begin{array}{l}\text { Number of criteria needed } \\
\text { to define low impact }\end{array}$} & \multicolumn{6}{|c|}{ Agreement between impact using clinical assessment or CAT (Kappa index) } \\
\hline & \multicolumn{3}{|c|}{ Adjustment by BODEx } & \multicolumn{3}{|c|}{ Adjustment by $\mathrm{FEV}_{1}(\%)$} \\
\hline & Global & $\begin{array}{l}\text { BODEx } \leq 2 \\
\text { and CAT } \leq 10\end{array}$ & $\begin{array}{l}\text { BODEx } \geq 3 \\
\text { and CAT } \leq 16\end{array}$ & Global & $\begin{array}{l}\text { FEV }_{1} \geq \mathbf{5 0} \% \\
\text { and CAT } \leq 10\end{array}$ & $\begin{array}{l}\text { FEV }_{10} \leq \mathbf{4 9 \%} \\
\text { and CAT } \leq 16\end{array}$ \\
\hline All criteria are met & 0.43 & 0.52 & 0.28 & 0.42 & 0.51 & 0.28 \\
\hline Three criteria are met & 0.37 & 0.22 & 0.61 & 0.45 & 0.39 & 0.58 \\
\hline Two criteria are met & 0.21 & 0.11 & 0.40 & 0.19 & 0.12 & 0.37 \\
\hline One criterion is met & 0.08 & 0.02 & 0.19 & 0.07 & 0.03 & 0.17 \\
\hline
\end{tabular}

Abbreviation: CAT, COPD assessment test. 
Table S4 Predictive capacity of a composite event (c-statistic) according to the number of criteria needed to define clinical impact

\begin{tabular}{|l|l|l|l|l|l|l|}
\hline \multirow{2}{*}{$\begin{array}{l}\text { Number of criteria needed to } \\
\text { define low impact }\end{array}$} & \multicolumn{4}{|l|}{ Predictive capacity of composite event (c-statistic) } \\
\cline { 2 - 7 } & \multicolumn{4}{|l|}{ Adjustment by BODEx } & \multicolumn{4}{l|}{ Adjustment by FEV $_{\mathbf{1}}(\%)$} \\
\cline { 2 - 7 } & Global & BODEx $\leq \mathbf{2}$ & BODEx $\geq \mathbf{3}$ & Global & FEV $_{1} \geq \mathbf{5 0 \%}$ & FEV $_{1} \leq \mathbf{4 9 \%}$ \\
\hline All criteria are met & 0.613 & 0.599 & 0.568 & 0.618 & 0.581 & 0.629 \\
\hline Three criteria are met & 0.639 & 0.586 & 0.628 & 0.637 & 0.615 & 0.632 \\
\hline Two criteria are met & 0.628 & 0.589 & 0.611 & 0.628 & 0.616 & 0.619 \\
\hline One criterion is met & 0.628 & 0.589 & 0.611 & 0.630 & 0.619 & 0.619 \\
\hline
\end{tabular}

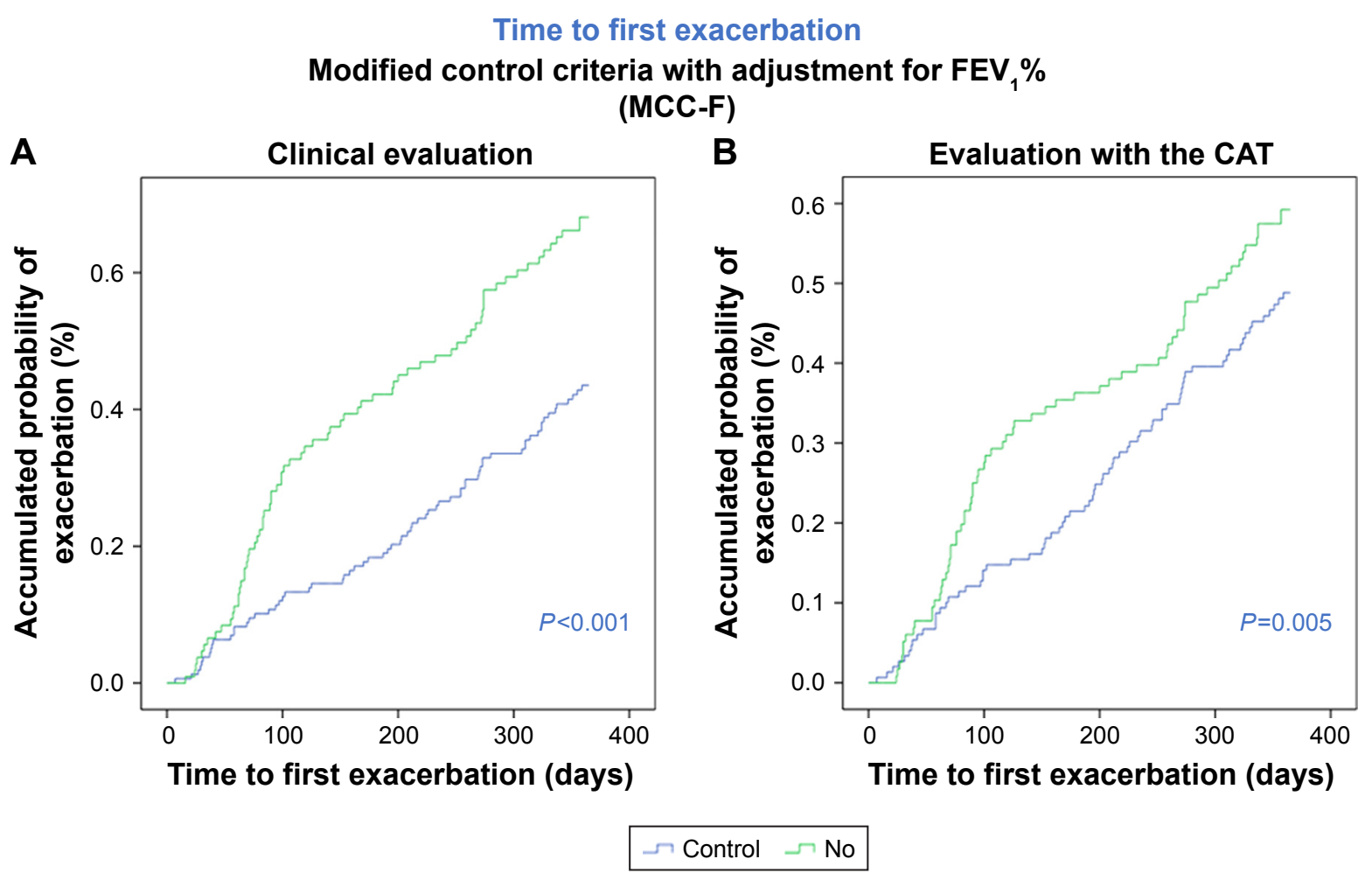

Figure SI Accumulated probability of exacerbation in patients controlled or non controlled according to modified criteria of control adjusted by FEV,\%. Notes: (A) control was defined by clinical evaluation; (B) control was defined using the CAT scores.

Table S5 CAT score at 12 months, according to different control criteria

\begin{tabular}{|l|l|l|l|}
\hline Criteria used & Control & Noncontrol & $P$-value \\
\hline OCC (clinical variables) & $4.7 \pm 3.0$ & $9.1 \pm 5.6$ & $<0.00 \mathrm{I}$ \\
\hline OCC (by CAT) & $5.4 \pm 4.0$ & $\mathrm{II} .1 \pm 5.4$ & $<0.00 \mathrm{I}$ \\
\hline MCC-B (clinical variables) & $5.8 \pm 4.0$ & $10.9 \pm 5.9$ & $<0.00 \mathrm{I}$ \\
\hline MCC-B (by CAT) & $6.1 \pm 4.4$ & $\mathrm{II} .0 \pm 5.8$ & $<0.00 \mathrm{I}$ \\
\hline MCC-F (clinical variables) & $5.5 \pm 3.7$ & $\mathrm{II} .0 \pm 5.8$ & $<0.00 \mathrm{I}$ \\
\hline MCC-F (by CAT) & $5.9 \pm 4.1$ & $\mathrm{Il} .3 \pm 5.4$ & $<0.00 \mathrm{I}$ \\
\hline
\end{tabular}

Abbreviations: CAT, COPD assessment test; MCC-B, modified control criteria adjusted by BODEx index; MCC-F, modified control criteria adjusted by FEV \%; OCC, original control criteria. 
International Journal of COPD

\section{Publish your work in this journal}

The International Journal of COPD is an international, peer-reviewed journal of therapeutics and pharmacology focusing on concise rapid reporting of clinical studies and reviews in COPD. Special focus is given to the pathophysiological processes underlying the disease, intervention programs, patient focused education, and self management protocols.

This journal is indexed on PubMed Central, MedLine and CAS. The manuscript management system is completely online and includes a very quick and fair peer-review system, which is all easy to use. Visit http://www.dovepress.com/testimonials.php to read real quotes from published authors 